\title{
A Game Development for Android Devices Based on Brain Computer Interface: Flying Brain
}

\author{
[Nilay Yıldırım, Mustafa Ulaş, Asaf Varol]
}

\begin{abstract}
The brain produces weak electrical signals that can be measured from the skull. Electroencephalography (EEG) is a method that provides monitoring electrical activity of the brain with the electrical methods. Brain Computer Interface (BCI) is a system that converts the electrical signals produced by the brain to the signals that can be interpreted by a computer or an electronic system. In the last decades, brain signals could be measured with systems requiring high costs, but nowadays, many EEG devices are available for personal use. These EEG devices and systems have their signal transformation methods. These EEG devices and their SDKs are available for developers and EEG devices are used for purposes such as playing game, psychological relief, monitoring body by daily users. In this study, 'Flying Brain ' game has been developed as BCI based and development stages have been discussed. NeuroSky Mindwave Mobile has been used as EEG device. The game is controlled by attention and meditation measurements obtained by converting the signals received from the user. In the game, the opportunities consist in case of high attention and meditation that will allow players to gain extra points. Consequently, the BCI game was interpreted in terms of Human-Computer Interaction and improvements can be made for BCI based games were discussed.
\end{abstract}

Keywords - Brain Computer Interface, Electroencephalography, Mobile, Android, Game Development, Human Computer Interaction

\section{Introduction}

Brain signals are one of the electrical signals produced by the body. Electroencephalography (EEG) is a method that enables measuring signals produced by the brain via electrodes or other electrical methods. Brain signals are converted through algorithms developed by the company and they are presented as a form that people can understand through their EEG devices and SDKs.

Nilay Yıldırım

Firat University

Turkey

Mustafa Ulaş

Firat University

Turkey

Asaf Varol

Firat University

Turkey
Measurement of brain activity, stimulation of the nerve tissue, advances in computer technology and robotic science allow interfacing between the human brain and artificial devices, these interfaces are called as Brain Computer Interface (BCI) [1]. BCI is not a system used to transmit outputs and commands to the world with normal ways, it is a type of communication system that recognizes and analyzes the brain activity [2]. BCI aims to produce the results of the signals that send via brain on computer systems rather than creating a reaction in the body.

Developers can write applications on EEG signals and brain signals integrated games, applications continue to be developed by these EEG devices produced by the company. These applications are available for many areas such as entertainment, medicine, sports, education, and psychology.

The computer game is games that consist of a defined set of goals or objectives and the players interact with each other in a computer-controlled virtual universe [3]. Today, BCI systems may be used as an input device to improve the game fun of people. EEG devices and brain signals began to take an important place for the gaming industry.

\section{Electroencephalography}

EEG, which is the part of Berger's psychophysical research for 40 years, had been the subject of his research since the beginning of 1890 and in the mid-1920s, the first human EEG was recorded by Hans Berger who will be called as "the father of electroencephalogram" [4].

Clinically EEG is used as helpful in the diagnosis of disorders such as sleep disorders and brain tumor, also today, EEG is used to create games and other personal applications. EEG signal has a wide frequency band $(0.5-\mathrm{H} 11 / 1)$ although clinical and physiological interest concentrated between 0.5 and $30 \mathrm{~Hz}$. This frequency range is divided into 4 frequency bands. These are [2] [5] [6]];

1) Delta $(\delta)$ Waves: Frequencies range from $0.5-4 \mathrm{~Hz}$, amplitudes $\mu v 20-400$. It is encountered in cases where the brain shows very low activity.

2) Theta $(\theta)$ Waves: Frequencies range from $4-8 \mathrm{~Hz} ; \mu \mathrm{v}$ amplitudes vary from 5-100. In normal individuals, it is encountered in the condition which the brain has lower activity such as dreaming sleep, medium depth of anesthesia and stress.

3) Alpha $(\alpha)$ Waves: Frequencies range from $8-13 \mathrm{~Hz}$; amplitudes vary between 2-10 $\mu \mathrm{v}$. They appear in the state of 
the absence of external stimulus, physical and mental rest state, closed eyes of individuals in the awake state.

4) Beta $(\beta)$ Waves: Frequencies are more than $13 \mathrm{~Hz}$. Amplitudes vary between 1-5 $\mu \mathrm{v}$. It is encountered in the phase of rapid eye movement when sleeping, in case of focused attention, mental work, sensory information processing, tension. Beta waves correspond to the highest activity levels of the brain [2].

\section{EEG, Human-Computer Interaction and Computer Games}

Human-Computer Interaction (HCI) is discussed in terms of human, computer and interaction. Interaction rates are considered for machines that require human-computer interaction, the need for a natural intuitive user interface that estimate and understand our intentions and show the characteristics of human-human interaction is increasing [7].

It is important to take into consideration of HCI factors and try to improve these factors as a priority on digital games. In previous years, input devices for the players were hardware devices such as joystick, mouse, keyboard and management arm. Today, the movements received from the user with the help of the camera, sounds and recent eye-tracking technology and EEG devices are used as input devices for players. Invasive EEG cannot be evaluated in terms of $\mathrm{HCl}$ [7], noninvasive EEG devices are used for the games.

When BCI is considered in the context of the game, it is thought that the cerebral activity can be considered as a skill or not and if this is true, it is also considered that this capacity can be increased [7].

Although, many BCI games are developed to satisfy psychological needs, success is not required to do so [8]. However, in some BCI systems, obtaining better performance from the systems with the results of the training of the users can verify that the brain activity is an ability. It is thought that these skills can increase the competitive factor which is the game play element.

When BCI is thought of in terms of game play, it seems to use three methods the game industry. Playing game is possible with brainwaves with or without using a joystick, keyboard or mouse devices which are well-known game input devices. Some constraints are faced when using brainwaves as an input device. Because the technology is still limited and only concentration and meditation or visual evoked potentials is not enough for games, some players think that they don't have total control like playing with a joystick [9].

Another purpose, game developers can measure some states of games such as boredom and excitement by using brainwaves for evaluating the efficiency of games. In this way, important feedbacks are taken for the game. Since 2004, EmSense has been using biofeedback to help game designers evaluate new products [10]. Finally, users can view their meditation and attention levels when playing a digital game.

\section{Iv. "Flying Brain" Game}

With the increasing importance of BCI, the effects of the games on BCI have been researched and games have been developed for this purpose. A game that can be played by an EEG device and brain signals was developed for Android based devices. For this purpose, Turkey themed "Flying Brain" game was developed.

\section{A. Hardware and Software}

The BCI based Android game was developed in the Eclipse platform using the Java Programming Language. The reason for the development of the game for Android devices can be listed as follows:

- Mobile platforms that the new size of the game experience is preferred due to the touch feature, ease of use, accessing in anywhere for small game experience and Android is determined as a mobile platform.

- The demand for devices and brands running the Android operating system is majority with $82 \%$ [11].

- Bluetooth access for Android devices and Bluetooth permit procedures for applications are easier.

NeuroSky Mindwave Mobile is used as EEG device. Brain-controlled games, applications are being developed Using NeuroSky technology. ThinkGear is the name of a single dry sensor technology that makes the measurement, filtering and analysis of EEG signals and brain waves and converts the user's brain signals to the shape information for applications using proprietary eSense algorithms of NeuroSky [12].

NeuroSky Mindwave Mobile uses TGAM module. TGAM is the first brain wave sensor developed for personal applications by NeuroSky and gives raw brain waves, inputs and outputs of the EEG power spectrum and states such as meditation and attention, measures EEG / ECG signal quality and detects the blink [13].

While alternating oscillation of mains frequency or electric frequency is $60 \mathrm{~Hz}$ in America and some Asian countries, it is $50 \mathrm{~Hz}$ in many countries of the world [14]. Therefore, Mindwave Mobile $50 \mathrm{~Hz}$ model for Europe was obtained.

\section{B. Development of The Game}

"Flying Brain" game is designed with the same function of Flappy Bird [15]. Progress of the Flappy Bird game is based on the principle that a bird flaps its wings for rising with each screen touch and fall down when not touching the screen. Meantime, while the bird is attempting to pass through the barrier, this passage gives 1 point to the player. The bird that hits the barriers or the ground dies and the game ends in this way. Attention and meditation waves are used as input to improve the competitiveness and the excitement of the game. Development stages in terms of the platform as follows: 
Proc. of the Intl. Conf. on Advances in Applied science and Environmental Technology - ASET 2015.

Copyright $(\odot$ Institute of Research Engineers and Doctors, USA .All rights reserved.

ISBN: 978-1-63248-040-8 doi: 10.15224/ 978-1-63248-040-8-46

- Firstly, Java has been selected as the platform and JDK and Eclipse IDE has been installed.

- The Android SDK has been downloaded and the installation for Android SDK for Eclipse has been completed.

- New project and related classes are created and graphic design and code writing were performed.

- ThinkGearBase. jar and ThinkGearPackX. jar libraries that are NeuroSky's library for Android have been added to the project.

- Bluetooth permission and other permissions are added to Android Manifest file.

- The preview of the game on Android 4.4.2 platform has been completed, but the preview for control BCI could not be realized due to the lack of Bluetooth permission of the Android Virtual Device.

- The game experiments made on the Samsung Galaxy Note 10.1 and the game has been completed.

The progress of the game is as follows;

- The user wears NeuroSky Mindwave Mobile device and the application that installed on the device performs a Bluetooth connection.

- When the game is opened, if the Bluetooth device is not available, "Bluetooth is not available" message is displayed to the user with a toast.

- ThinkGear (TG) and device connection status are indicated at the top of the game as centered as in Figure 1. For example "Connecting..." "Connected.".

\section{$66 \quad$ Bağlandı $\quad 47 \leq$ \\ Figure 1. Connecting information of the device}

- Measurements of meditation and attention level representation in the game were visualized with a progress bar as in Figure 1.

- While the brain that designed as the main character passes through the barrier, this passage gives 1 point to the player.

- e-SENSE measurement has been developed for NeuroSky devices specially and is based on the conventional EEG measurements. Attention and Meditation values were scaled between 1 to 100 and evaluation of the rating scale is as follows [16]:

- Measurements between 40 and 60 are considered as "neutral ".

a) It is accepted as a little high between 60-80.

b) It is accepted as high between 80-100.

c) Values between 20 -40 are considered as low.

d) Values between 1-20 are shown to be very low

- Game starts automatically when the player's attention value rises above 80 .

- Attention level is obtained by measuring beta waves. When the player's attention gets over 80 levels 10 times, extra 10 points are gained as shown in Figure 2.
A visual that represents extra 10 points is shown to the user.

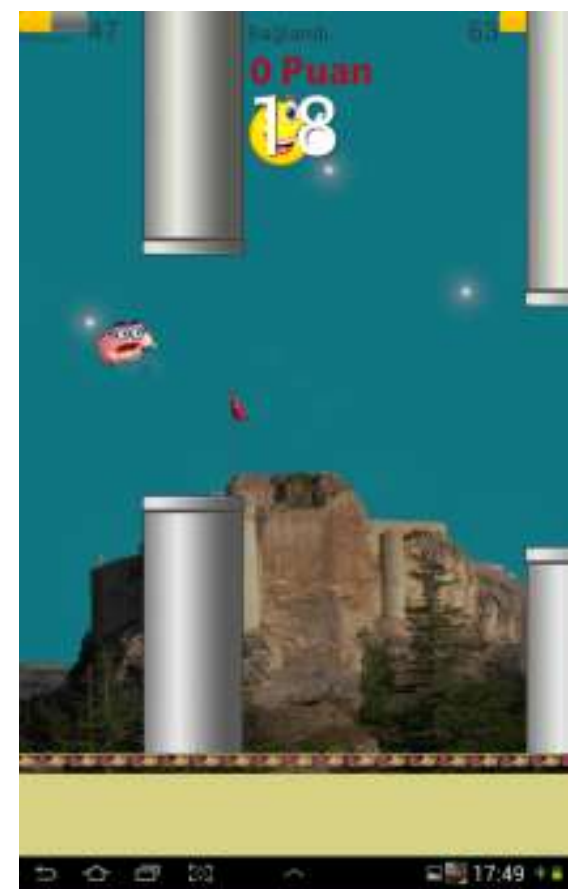

Figure 2. Gaining 10 point in case of attention

- Meditation represents the player's mental calmness and it is obtained by the measurement of alpha waves. When the player's meditation gets over 80 levels, maps that give extra 1 point to the player are displayed on the screen as in Figure 3. When meditation level drops below 80 , new maps are out on the screen.



Figure 3. The maps are shown on screen in case of meditation

- The player's score instantly appears in the top middle of the screen. When the character is crashed to the barrier or fallen down by the player, the game ends.

- Players can see the score and the highest score in the game. 
Proc. of the Intl. Conf. on Advances in Applied science and Environmental Technology - ASET 2015.

Copyright $(\odot$ Institute of Research Engineers and Doctors, USA .All rights reserved.

ISBN: 978-1-63248-040-8 doi: 10.15224/ 978-1-63248-040-8-46

- Also, the game is designed to be played without using the EEG device. Users may play the game without EEG device, but they can't earn extra points.

\section{Coding Of The Game}

TG device communicates with application by messages sent to a Handler object and these messages are transmitted within the msg.what object. The codes about Bluetooth connection and the connection of the device as shown in Figure 4.

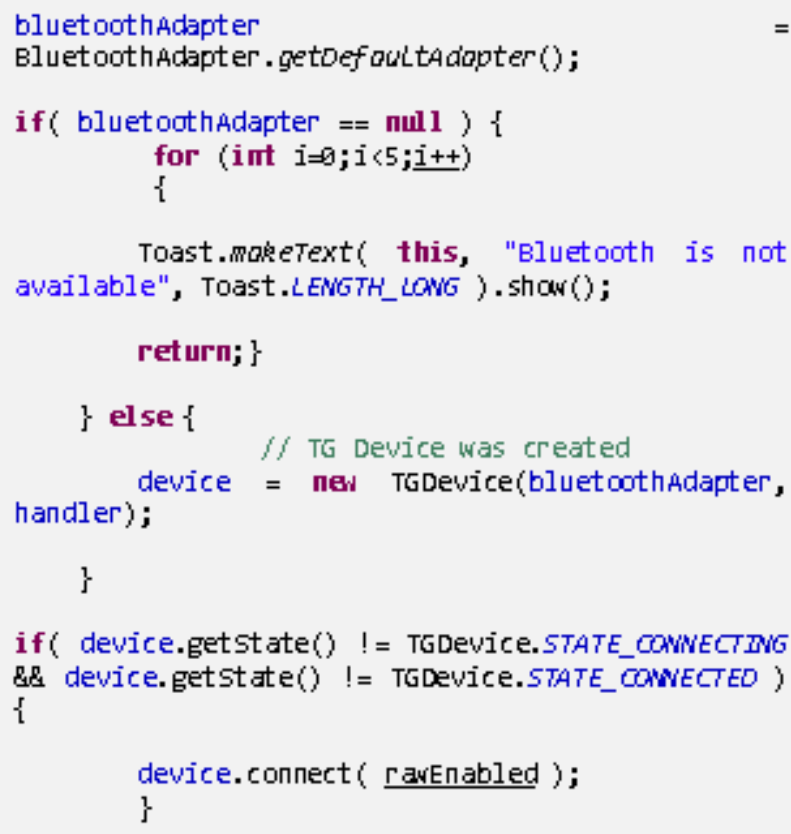

Figure 4. Bluetooth and TG device connection codes

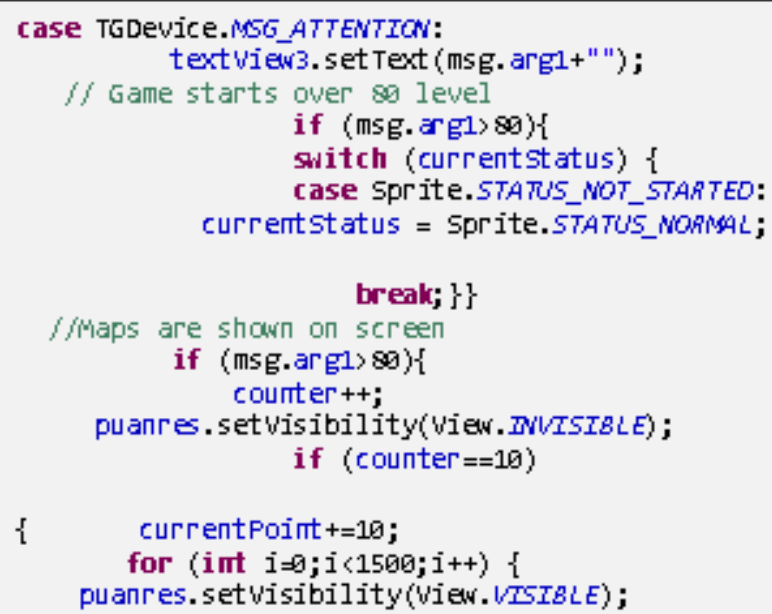

Figure 5. Codes for attention state
When the player's attention level rises above 80, game starts automatically. Also, when the player's attention gets over 80 levels 10 times, it is gained an extra 10 points. The codes for attention level are as in Figure 5.

Maps are displayed on the screen when the player's meditation level is over 80. A map gives 1 point to the player when it is collected. Meditation status codes are in Figure 6.



Figure 6. Codes for meditation state

\section{v. Conclusions and Recommendations}

The game was developed according to the operation of "Flappy Bird" [15] game that is the one of most played mobile games of 2013-2014 years. It is aimed to directing the game using EEG device by the player thanks to the attention and meditation signals which are the sensory signals. While the movement of game character is sensitive even the touching input, it is not possible to move our character to the desired direction with brain signals. According to Gürkök [8], if the $\mathrm{BCI}$ is used for critical operations such as moving game character, the control cannot be achieved effectively, the users want manual control. In this case, using the signal only to increase the game score has been appropriate for this game type. According to the research of Gürkök [8], only attention is not enough to control the $\mathrm{BCI}$ game and the players want to use other controllers. Therefore, it is important to have used the EEG signals with touch input.

Personal evaluation of the game and EEG system can be stated as follows;

- Development of the game as Android-based has provided to user transport and the ability to access the game from anywhere. 
Proc. of the Intl. Conf. on Advances in Applied science and Environmental Technology - ASET 2015.

Copyright $(\odot$ Institute of Research Engineers and Doctors, USA .All rights reserved.

ISBN: 978-1-63248-040-8 doi: 10.15224/ 978-1-63248-040-8-46

- The appearing of the ProgressBar on the screen is important in terms of obtaining information of users about their attention and meditation states and hence obtaining information about the progress of their game score.

- Some negative situations can be encountered such as late device connection while establishing NeuroSky connection and lack of connection with the game although providing Bluetooth pairing.

- NeuroSky device provides great convenience to users in terms of $\mathrm{HCl}$ in spite of the multi-channel electrode system and the wired EEG devices.

Playing the game by EEG device has been effective in terms of affecting the game score and adding excitement to the game. Players try to provide less stress and higher attention. The progress of the game can be changed as depending on brain signals and the signals may affect the game much more. Evaluation of the game by the users will help understanding the importance of BCI game. So, evaluation and comparison of this BCI game with original "Flappy Bird" game by the users can be next study.

\section{References}

[1] N. G. Özmen, Beyin Bilgisayar Arayüzü Tasarmı İçin Farklı Zihinsel Aktiviteler Esnasında Oluşan EEG İşaretlerinin Analiz Edilmesi Ve Sinıflandırılması, Trabzon / Turkey: Karadeniz Technical University, 2010.

[2] A. Sayın, Beyin Bilgisayar Arayüzü Tasarımı, İstanbul: İstanbul University Fen Bilimleri Enstitüsü, 2008.

[3] I. McMillan, "The Irresistible Art of Video: Implementing Digital Video in Middle Years Art", 2007. Available: http://www.ingridmcmillan.com/images/ingrid_mcmillan_thesis.pdf. ,3072010.

[4] D. Millett, "Hans Berger: From Psychic Energy to the EEG", Perspectives in Biology and Medicine, vol. 44, no. 4, pp. 522-542, 2001.

[5] Ö. Aydemir and T. Kayıkçığlu, "EEG Tabanlı Beyin Bilgisayar Arayüzleri"," Akademik Biliş̧im'09 - XI. Akademik Bilişim Konferansı Bildirileri, Şanlıurfa,Turkey, 2009.

[6] S. Daşdağ, "Elektroansefalografinin (EEG) Biyofizik Temelleri", 2010. Available: www.dicle.edu.tr/a/dasdag/EEG.ppt.,18 072013.

[7] H. Gürkök, "Mind the Sheep! User Experience Evaluation \& BrainComputer Interfaces and Games", University of Twente, Netherlands, 2012.

[8] H. Gürkök, B. v. d. Laar, D. P.-O. Bos, M. Poel and A. Nijholt, «"Players' Opinions on Control and Playability of a BCI Game", Universal Access in Human-Computer Interaction. Universal Access to Information and Knowledge, vol. 85, no. 14, pp. 549-560, 2014.

[9] T. Hay, "Mind-Controlled Videogames Become Reality", http://online.wsj.com/, $\quad 4 \quad 2012.2$ Available: http://online.wsj.com/article/SB10001424052702304707604577426251 091339254.html.,17 72013.

[10] D. Graham-Rowe, "Let the mind games begin", New Scientist, vol. 198, no. $2647,2008$.

[11] Gartner, "Gartner Says Smartphone Sales Accounted for 55 Percent of Overall Mobile Phone Sales in Third Quarter of 2013", November 2013. Available: http://www.gartner.com/newsroom/id/2623415., 01 2014.

[12] NeuroSky Inc., "What is ThinkGear?", NeuroSky Inc., 2014. Available: http://support.neurosky.com/kb/science/what-is-thinkgear., 25122014.
[13] NeuroSky Inc., TGAM, NeuroSky, USA, 2011.

[14] Wikipedia, Utility frequency, Wikipedia, the free encyclopedia, 2012. Available: http://en.wikipedia.org/wiki/Utility_frequency. , 18122014.

[15] D. Nguyen, "FLAPPY BIRD", dotgears, 24 May 2013. ,Available: http://www.dotgears.com/apps/app_flappy.html., 22122014.

[16] NeuroSky Inc., "ThinkGear Development Guide for Android", NeuroSky Inc., USA, 2012.

About Author (s):

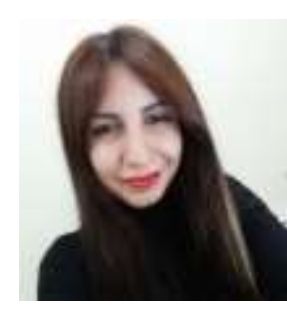

Nilay Yildirim is a $\mathrm{PhD}$ student of Software Engineering Department at Firat University. She is a research assistant in Software Engineering Department at Firat University in Turkey.

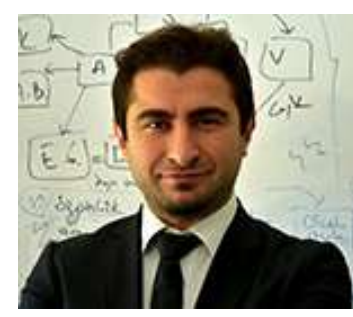

Mr. Dr. Mustafa Ulaş has received BS degree in 2003 then he got $\mathrm{PhD}$ title in Electric and Electronics Engineering Dept. of Firat University. Between the years 20042012 he worked as Lecturer in Dept. of Informatics, at the same time he was software developer and was manager of R\&D Department. Mr.Dr.Ulaş was vice president of Computer Center and Dept. of Informatics in 2008-2012. He worked for University of Michigan in USA as visitor researcher in 2013.

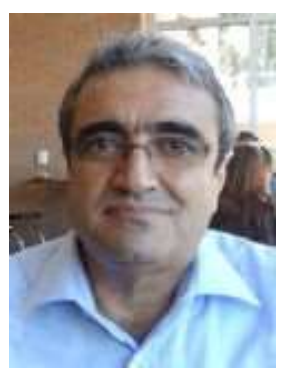

Dr. AsafVarol

Dr. Varol is the Chair of the Department of Software Engineering at Firat University/TR. His research interests are in software engineering, digital forensics, social media applications and knowledge management. He is the Founder of the Digital Forensics Department at Firat University. 